\title{
УДК 53.09
}

\section{ДЕЙСТВИЕ ЖИДКОЙ СРЕДЫ НА ПОЛИМЕРНЫЕ КОМПОЗИЦИОННЫЕ МАТЕРИАЛЫ}

\author{
Акаева Маднат Магомедовна \\ к.т.н., доцент \\ ФГБОУ ВО «Чеченского государственного университета» \\ Академия наук ЧР
}

Аннотация: В работе исследовано влияние воды на массы образцов полимерного композиционного материала ненагруженном состоянии при температуре $20-25^{\circ} \mathrm{C}$. Показано, что композиционный материал на основе полиамида и полипропилена, более стойкий при выдержке в жидкой среде при этом возможно, изменения основных физико-химических свойств незначительны. Для каждой полимерной композиции экспериментально определены изменение массы в зависимости от времени выдержки в воде. На основании результатов, можно сделать вывод, что полипропилен и полиамид модифицированные высокоэффективным модификатором (z) демонстрируют более устойчивы к воздействию воды.

Ключевые слова: полиамид, полипропилен, агрессивная среда, композиционный материал, модификатор.

\section{EFFECT OF A LIQUID MEDIUM ON POLYMERIC COMPOSITE MATERIALS}

\section{Akaeva Madnat Magomedovna}

\begin{abstract}
The paper investigates the effect of water on the masses of samples of polymer composite material in the unloaded state at a temperature of $20-25^{\circ} \mathrm{C}$. It is shown that a composite material based on polyamide and polypropylene, which is more stable when exposed to a liquid medium, while it is possible, changes in the basic physical and chemical properties are insignificant. For each polymer composition, the weight change was experimentally determined as a function of the exposure time in water. Based on the results, it can be concluded
\end{abstract}


that polypropylene and polyamide modified with a high-performance modifier (z) are more resistant to water.

Key words: polyamide, polypropylene, aggressive environment, composite material, modifier.

В процессе эксплуатации изделия из полимерных материалов подвергаются воздействию внешней среды. В результате такого воздействия исходные свойства материала могут значительно изменяться. Изменение массы образца полимерных материалов при выдержке в агрессивной среде в течение различного времени, как правило, показатель протекания физических или химических процессов в полимерном материале. Сорбция агрессивных сред вызывает, как правило, ослабление межмолекулярного взаимодействия в полимерах. В результате протекания этих процессов могут происходить изменения физико-химических свойств полимеров. Процесс изменения физических свойств могут быть как обратимым, так и необратимым [1, с. 91]. Среди полимеров полиамид и полипропилен имеют практическое значение и обладают комплексом ценных свойств и доступны экономически. В тоже время, полиамид является конструкционным и волокнистым материалом и имеет существенные недостатки, способность впитывать жидкую среду ограничивает область применения [1, с. 17]. Полиамиды могут сорбировать из окружающей среды до 10\% (масс.) воды, в результате чего значительно изменяются их физико-механические свойства. Поскольку сорбция жидкой среды зависит от многих факторов, которые не всегда можно установить, нужно в каждом конкретном случае экспериментально определить изменения массы, размеров образца при выдержке в жидкой среде [1, с. 57, 2, с. 27]. В связи с этим представляло интерес, исследование влияние агрессивных сред на полимерные композиционные материалы.

В работе исследовали ПП и ПА, модифицированные ультрадисперсными частицами высокодисперсной смеси $(70 \div 120 \mathrm{Hм}) \mathrm{Fe} / \mathrm{FeO}$ (z) в концентрациях 0,05 и $0,1 \%$. Испытания полимерных материалов, перерабатываемых литьем под давлением на стойкость к агрессивным средам, проводили в соответствии с ГОСТом-12020-72. Образцы для испытания готовили прессованием в форме пластин длиной 38 мм и толщиной $3 \pm 0,2$ мм, 12,5+0,5 мм. На поверхности пластин не должно быть загрязнений, следов краски, масляных пятен и наличие каких-либо мелких трещин. 
Затем образец взвешивали с точностью до 0,002 грамма и помещали в сосуды с дистиллированной водой. В один сосуд допускается помещать не более 5 образцов, изготовленных из одного и того же материала, при этом заметим, что образцы не содержат экстрагированных веществ. Образцы помещали в сосуд так, чтобы они были полностью погружены в реагент, не соприкасались друг с другом и со стенками сосуда. Испытания проводили при комнатной температуре в течение 5 суток. Причем в процессе испытания проводили измерения массы образцов через 12; 24; 36; 48; 72; 96 и 120 часов.

Агрессивную жидкую среду в ходе изменения массы образцов перемешивали при помощи мешалки не реже одного раза в сутки и периодически контролировали количество реагента в сосуде.

После окончания испытания образцы вытирали не ворсистым материалом, взвешивали и определяли изменение массы $(\Delta \mathrm{m})$ по формуле:

$\Delta m=\left(m_{1}-m\right) \times 100 / m$

где $\mathrm{m}$ - масса испытуемого образца до первого погружения его в реагент, г; $\Delta m$ - масса испытуемого образца после выдержки его в реагенте, г.

Результаты измерений позволяют построить график зависимости рис. 1 и 2.

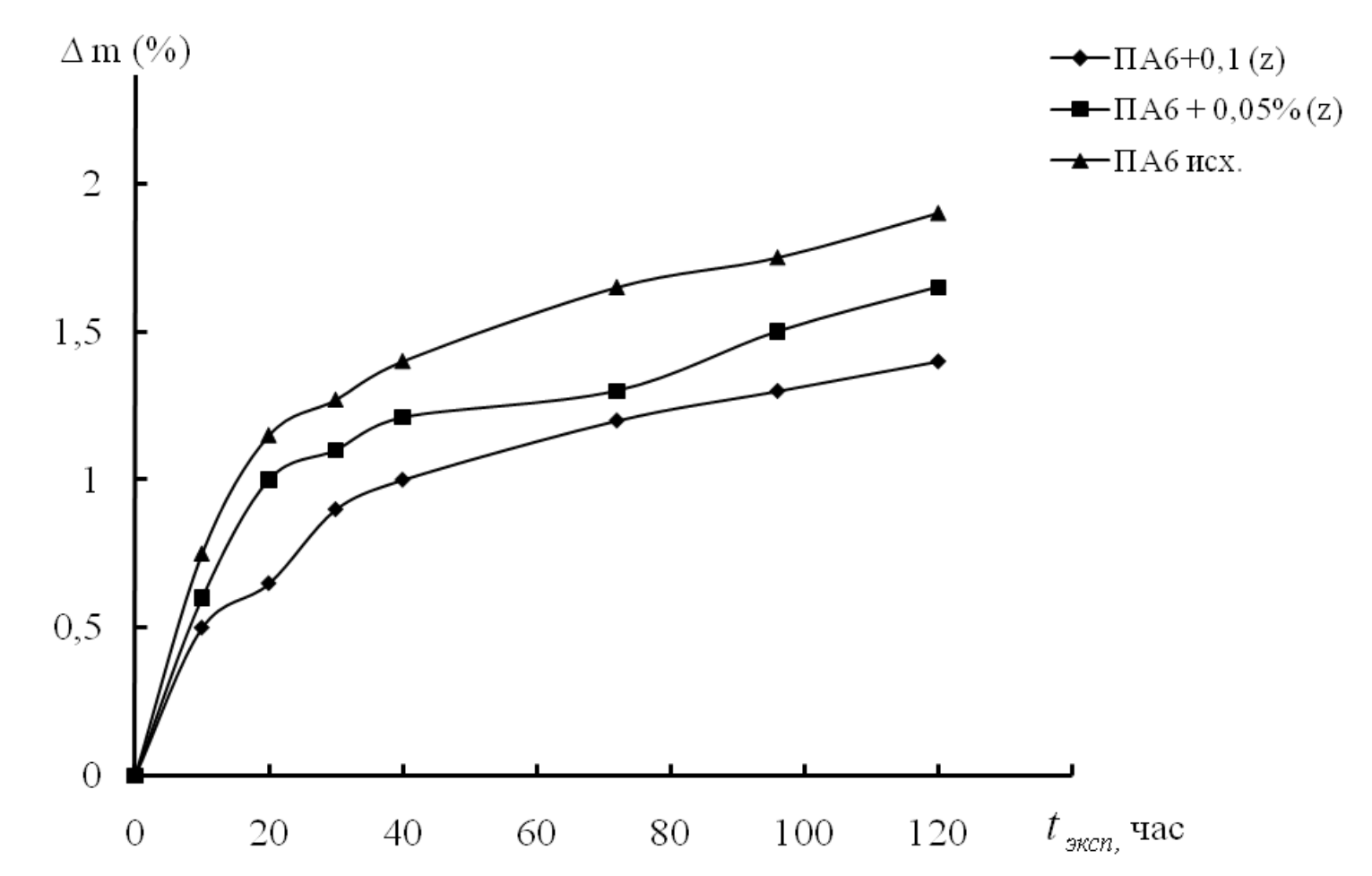

Рис. 1. Зависимость изменения массы $\Delta \mathrm{m}(\%)$ ПА6 и полимерного композиционного материала ПА6+(z) от времени выдержки $\mathrm{t}$ (час) в $\mathrm{H}_{2} \mathrm{O}$ 


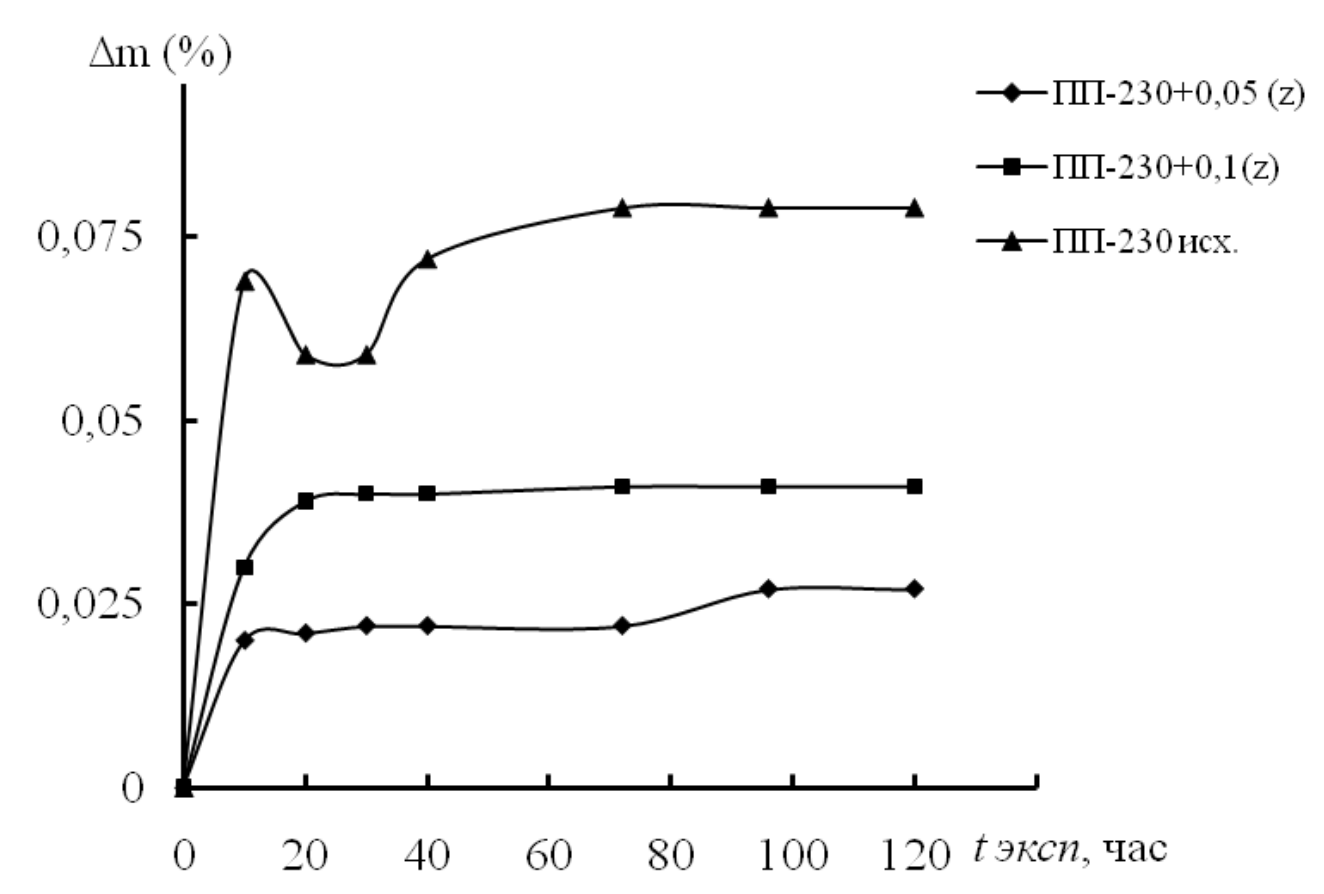

\section{Рис. 2. Зависимость изменения массы $\Delta \mathrm{m}(\%)$ ПП и полимерного композиционного материала ПП+(z) от времени выдержки t (час) в $\mathrm{H}_{2} \mathrm{O}$}

При выдержке ненапряженном состоянии полимеров в физически активных средах может происходить набухание полимерного материала, предельным случаем которого является растворение. При набухании в физически активных средах обычно понижаются прочностные свойства полимерного материала, тем самым повышается эластичность полимерного материала. Прочностные свойства полимерных материалов, возможно, понижаются возникновением внутренних напряжений вследствие неравномерности набухания, в результате, полимерном материале могут образовываться внутренние дефекты, также может изменяться вследствие изменения межмолекулярного взаимодействия, происходящего в процессе набухания полимера. Вместе с тем, жидкая среда в процессе набухания полимера может способствовать изменению основных физико-химических свойств [1, с. 152].

Масса образцов КМ на основе ПП и ПА экспонированные в агрессивной среде в течение различного времени остается на уровне по сравнению с исходным ПА и ПП. Значение массы исходного ПП понижается в области 20 30 час. экспонирования, где предположительно происходит адсорбциядесорбция, такое поведение полимерных материалов ранее отмечалось исследователями [1, с. 71]. Сорбция воды в течение различного времени 
образцами композиционного материала значительно меньше рис. 1, 2 по сравнению с исходными образцами. Следовательно, этот факт доказывает, что физико-механические свойства композиционного материала на более высоком уровне, чем у исходных образцов. Проведенные исследования позволяют сделать вывод, что высокодисперсная смесь $\mathrm{Fe} / \mathrm{FeO}$ является эффективным модификатором для ПП и ПА и может быть, использована в качестве ингредиента повышающего стойкость к агрессивным средам.

\section{Список литературы}

1. Воробьева Г.Я. Химическая стойкость полимерных материалов, М.: Химия. $-1981 .-293$ с.

2. Действие агрессивных жидких сред на композиты полипропилен $/ \mathrm{Fe} / \mathrm{FeO}$ Акаева М.М. //Известия Чеченского государственного университета. 2018. - № 2 (10). - С. 26-27.

3. Волынский А.Л., Ярышева Л.М., Уколова Е.М., Козлова О.В., Вагина Т.М., Качекьян А.С., Козлов П.В., Бакеев Н.Ф. О двух механизмах действия физически агрессивных жидких сред на механические свойства и структуру полиамида-6. //Высокомолек. соед. - 1987. - Т 29 А. - № 12. - С. 2614-2619.

(C) М.М. Акаева, 2021 